\title{
Gerações e famílias: Polissemia, mudanças históricas e mobilidade
}

Parry Scott ${ }^{1}$

Resumo: Uma revisão selecionada da literatura nacional e internacional sobre família e gerações mostra como transformações nas relações de poder entre nações favorecem ênfases históricas diferentes de hierarquia, solidariedade, desigualdade e direitos. Quando se refere à família para embasar identidades e relações entre nações e povos, ela se relaciona com o "enquadramento hierárquico" e a "integração, padronização e incorporação". Evolucionismo, personalidade e cultura, estrutura-funcionalismo e urbanização e modernização realçam hierarquias, unificação e estabilidade, restringindo a discussão de gerações a cumprir uma agenda semelhante. Quando se refere à família como meio de resistência contra a desigualdade, discutem-se "modos de produção, contenção de pobreza e planejamento reprodutivo" e abre mais espaço para a discussão de gerações como grupos etários desiguais, apartes, com interesses próprios. Esta abordagem intensifica-se com o realce à pluralidade e fragmentação da família no mundo global, permitindo que gerações recebam tratamento como grupos com iguais direitos à diversidade com culturas próprias, parcialmente dissociadas de famílias. Discute-se como migração e mobilidade se articulam diferentemente diante da ambiguidade e polissemia de relações intergeracionais e família. Palavras Chaves: famílias, gerações, polissemia, mobilidade, nações, poder.

Os netos foram inventados para, mais uma vez, nos roubarem a regalia de sermos nós. [...] primeiro, não fomos porque éramos filhos. Depois, adiamos o ser porque fomos pais. Agora queremnos substituir pelo sermos avós.

O adiado avô, Mia Couto.

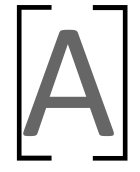
ambiguidade, na fala de um avô em busca da sua individualidade no conto de Mia Couto, revela tensão que marca a vivência contemporânea das gerações. No final do conto, o avô queixoso é descrito por sua mulher, que, ao perceber o apego ao neto com quem adorme-
1. Professor Associado do Departamento de Ciências Sociais, Programas de PósGraduação em Sociologia e em Antropologia da Universidade Federal de Pernambuco. Scott ${ }^{\circ}$ hotlink.com.br. 
ce no sofá, declara: "Seja meu filho, Zedmundo, me deixe ser sua mãe. E vai ver que esse nosso neto nos vai fazer sermos nós, menos sós, mais avós". A mulher reinterpreta as relações sociais que o homem identifica como negando a individualidade, como meio de chegar à sua própria confirmação. Ele, receoso de ser substituído, encontra, pelo menos na percepção de sua mulher, uma individualidade subjetiva, justamente por estar inserido em relações intergeracionais que dão um significado à vida. Geração, neste sentido, é mais que idade, por suas implicações como relações sociais. Opera simultaneamente hierarquizando por diferenças de gerações, e solidarizando vertical e horizontalmente, em torno de relações de imagens de pertencimento familiar em constante negociação. Há um habitus familiar e histórico sempre em transformação, contestado e reafirmado, que dá dimensões concretas para a ação e a significação na relação entre família e gerações. As polissemias - gerações e família são termos com múltiplos sentidos - e a mobilidade - deslocamentos de pessoas entre grupos geográfica ou socialmente distintos - permitem uma ambiguidade na qual nem às gerações, nem às famílias se possa atribuir interpretações unívocas. Este trabalho mostra como algumas transformações nas relações de poder entre nações favorecem ênfases particulares em tempos diferentes, passando pelo realce da hierarquia, da solidariedade, da desigualdade e dos direitos.

Uma revisão selecionada de alguns textos da literatura nacional e internacional sobre estudos de família e gerações identifica discursos históricos e teóricos diversos que têm dado dimensões a recorrências em ênfase durante períodos diferentes. Discute-se também como migração e mobilidade articulam-se diferentemente diante da ambiguidade de relações intergeracionais, articulando sentidos em tempos diferentes. Discutir os contextos de poder que influenciam arranjos geracionais entre jovens, adultos e idosos (filhos, pais, avós, netos), em diferentes situações de escolhas de objetos e de mobilidade, evidencia como a inserção em redes de relações familiares revela sintonias e dissintonias entre gerações e família. No percurso, elaboram-se ideias sobre a afirmação da individualidade, o reforço da interconexão familiar, as negociações de poder entre homens e mulheres, o traçado das fronteiras entre gerações e o apelo político à pluralidade de direitos; argumenta-se em favor da compreensão de poder, gênero, individualidade, pertencimento familiar e direitos para abordar gerações no estudo da pluralidade de famílias contemporâneas e seus patrimônios materiais e sociais. 


\section{Polissemia e mobilidade de famílias e gerações}

A polêmica em torno do que constitui uma família já gerou quase tantas definições quanto autores. Ressaltar um aspecto ou outro dos elementos constituintes evocados em trabalhos distintos revela mais sobre as preferências teóricas dos autores do que sobre o que é mesmo uma família. Não poderia haver "um lugar" da ideia de gerações nestes estudos e sim uma série de interseções entre gerações e família que desvendam diferentes questões. Os autores - sendo estudiosos preferenciais de famílias ou de gerações - necessariamente lidam com a polissemia de ambos os conceitos. Estas polissemias resultam simultaneamente em vantagens e limitações, como bem aponta Klaas Woortmann (1984).

A migração - uma mobilidade que frequentemente resulta em deslocamentos geográficos e sociais - apresenta um desafio para os estudos sobre família e gerações, já que leva a inserções em novas realidades de interpretações e de relações que precisam ser equacionadas para se entender as transformações e os mecanismos que dão continuidade ao sentimento de pertencimento a grupos familiares e de parentesco em espaços diferenciados. Este assunto é um dos focos entremeados ao longo do trabalho e abordado mais especificamente nos comentários finais.

Retomo o estudo "Família, gênero e poder no Brasil no século XX" (Scott, 2004), com atenção para a articulação entre gerações e família de acordo com o tempo histórico e os diferentes destaques que reportam a configurações de relações de poder entre nações. Os tempos históricos são de datas imprecisas por uma intenção dupla: primeiro, mostrar que abordagens privilegiadas num período estão sempre presentes em outros períodos subsequentes ou precedentes; e, segundo, reconhecer a opção brasilcêntrica de um relato sobre eventos de relações internacionais cujas cronologias variam de acordo com a nação de cuja perspectiva se olha. Neste percurso histórico, sobrepõem-se perspectivas de família e gerações que se coadunam, pelo menos parcialmente, com estas relações. Nenhuma perspectiva se perde com a passagem entre períodos de realce de quadros de interpretação, apenas havendo rearticulações de ênfases em tempos históricos e recortes sociais e culturais diferentes.

"Gerações históricas" são percebidas pelas perspectivas de tempos em transformação; e "gerações de parentesco e de família" são ordenadas em estruturas que perduram, mesmo se sujeitas a oscilações. Gerações etárias 
também são diferentes de gerações de família e de parentesco. Para entender a relação entre famílias e gerações, o recurso heurístico a uma sequência de quatro tempos históricos precisa ser entendido como uma construção de configurações (no sentido proposto por Elias, 1990) de referências gerais, situadas em relações concretas que não são presas estreitamente a datas ou a locais específicos (Tavares, 2009). Há períodos com diferentes ênfases que influenciam o pensamento social sobre nações, famílias e gerações. Estes tempos são descritos como de "enquadramento hierárquico", "integração, padronização e incorporação", "modos de produção, contenção de pobreza e planejamento reprodutivo" e de "direito à diversidade".

\section{Enquadramento hierárquico (hierarquia)}

O tempo histórico - "enquadramento hierárquico" - tem seu auge no final do século XIX e início do século XX. Usa ideias de raça e clima para reafirmar ordens sociais hierárquicas. Famílias e gerações, conhecidas superficialmente, têm pouca problematização, fora a sua inserção em esquemas evolutivos que sugerem as origens da configuração de relações entre as nações colonizadoras e os povos colonizados.

No seu afã de confirmar o alinhamento entre as nações, alguns autores evolucionistas - como Morgan (1976) e Engels (2007) - procuram ordenar hierarquicamente sociedades numa escala atemporal de acordo com diferenças de tecnologia e organização social. Neste procedimento, usam um idioma de família: famílias consanguíneas, punaluanas, sindiásmicas e monogâmicas, numa sequência determinada, pinçadas de exemplos concretos do mundo como era conhecido e interpretado nos finais do século XIX. Realçam reconhecimento de pertencimento ao grupo de acordo com regras das escolhas dos cônjuges e na perpetuação do grupo. Não se desenvolvem reflexões com maior poder explicativo sobre gerações, preferindo-se referir-se a redes amplas de parentesco que informam sobre linhas masculinas ou femininas de passagem de patrimônio material e identitário do grupo. As etapas delineadas são mais importantes que as relações intergeracionais em si, cujas linhas de autoridade estão tratadas como pressupostas. Mesmo com a especulação sobre as origens, o olhar é predominantemente sincrônico, pois as histórias de um lugar ou outro, bem como as transformações decorrentes de contatos não constituem parte privilegiada do quadro interpretativo.

Para populações coloniais ou primitivas que aspiram a um reconhecimento da sua importância entre as nações, se esboça um quadro de deslegitimação 
geracional no qual os filhos de casamento mistos racialmente anulam as suas pretensões de enquadramento mais alto nas hierarquias internacionais devido às suas implicações para a composição racial das gerações mais novas de sua população.

A mobilidade espacial entre gerações e famílias recebe pouquíssima atenção dos autores mais evolucionistas que reafirmam as estruturas de hierarquias. O difusionismo, em uso por outros autores no mesmo período, realça uma história composta por traços culturais em circulação entre diferentes círculos culturais que manifestam tradições em contato, com pouca atenção à circulação de pessoas entre gerações e famílias. Adeptos da ideia de "perfectibilidade racial" da população, mediante a introdução de novas populações de traços superiores, defendem a imigração para as (ex)colônias no intuito de criar novas gerações de populações menos corrompidas pela mistura entre raças.

\section{Integração, padronização e incorporação (solidariedade)}

No segundo período - que abrange a primeira metade do século XX - enfatizam-se ideias de "integração, padronização e incorporação". É um período de centralização de Estados e de conflitos internacionais intensos rumo a uma troca histórica de hegemonias nacionais, passando internacionalmente da Europa para os Estados Unidos.

Elabora-se um discurso de abstração e teorização sobre estruturas de personalidade e funções integradoras que trata a família como base para as relações sociais de cada nação/povo e efetiva este discurso com atenção a configurações sociais e culturais de relações entre gerações, primeiro, na perpetuação das estruturas e, posteriormente, no questionamento de seus mecanismos de transformação histórica. Famílias nucleares e famílias patriarcais exercem funções integradoras de acordo com os códigos de cada povo e nação estudados, socializando para a estabilidade a reprodução de padrões e a incorporação na nova reordenação mundial.

A história se faz mais presente nas interpretações, superando a atemporalidade de esquemas evolutivos. Ao mesmo tempo, há uma busca de lógicas internas funcionais das instituições (tratadas por muitos como ainda sincrônicas). Na diversidade de ideias sobre gerações e sua relação com famílias, soergue-se a família nuclear ou conjugal a uma posição central na construção de esquemas interpretativos. 
Melhora a qualidade das informações provenientes da valorização de pesquisa de campo em lados diferentes do Atlântico. Franz Boas ressalta os significados elaborados por pessoas em culturas cujas histórias se formam por convergências particulares irreplicáveis. Bronislaw Malinowski enxerga pessoas, de carne e osso, com as quais se precisa conviver para integrar a maneira de ser e o ponto de vista do nativo para descrever a sua cultura de uma forma mais verossímil e mais sensivelmente humana que as abordagens que o precedeu.

A perspectiva valoriza a autoridade de pessoas que dominam os princípios organizacionais de suas sociedades concretas, ora pelos códigos culturais de socialização e formação de personalidade, ora pela operação de estruturas sociais que reproduzem uma funcionalidade individual e social, de sobrevivência e de estabilidade, ora pela reiteração de histórias sequenciadas de progresso e mobilidade que passam do folk para o urbano.

Numa vertente desta literatura - elaborada a partir das ideias de Boas -, a personalidade deriva da cultura. Nos Estados Unidos, Ruth Benedict, Margaret Mead e Ralph Linton concatenam configurações específicas de culturas que produzem personalidades diferentes observadas nas atividades cotidianas familiares no ciclo de vida: nascimento, cuidado e criação infantil, iniciação de jovens, cortejo e casamentos, provimento e liderança, e trato dos mortos. O domínio adulto destas práticas confere um espaço privilegiado de referência e repasse da cultura. O espaço de "contestação" é bastante reduzido, contemplado complementarmente com menção de desvios, doenças e outras formas de excepcionalidade. Em suas biografias individuais, a reflexão de todos estes autores, sem perder a preocupação com padrões identificados entre povos "primitivos", torna-se mais explicitamente dirigida para a nação ocidental, encarnada, sobretudo, no modelo americano.

Mead, em seus estudos de sociedades tribais das ilhas do Pacífico, contribui, junto com Gregory Bateson, com uma extraordinária documentação das relações entre mães e filhos (Mead e Bateson, 1970). A antropóloga, em Sexo e temperamento (1969) Adolescência em Samoa (2001), entre outros textos, exorta comparações entre a América e outros povos para mostrar que os comportamentos respondem mais à cultura que à biologia, clamando isso como lição para as maneiras com as quais os adultos veem e interagem com os jovens e as jovens. Após a Segunda Guerra Mundial, o seu livro sobre o conflito entre gerações (1970) dá realce às nações modernas. Abor- 
da como o avanço rápido da tecnologia (exemplificado pelo poder de destruição da bomba atômica) pretere a autoridade dos adultos por causa das novas exigências para adquirir e repassar este conhecimento. Detecta-se um certo saudosismo da autoridade adulta com base na detenção de um conhecimento cultural duradouro, enquanto detalha culturas como préfigurativas (o conhecimento de anciões é guia e referência moral para as gerações subsequentes), figurativas (o conhecimento é adquirido com uma simultaneidade entre gerações) e pós-figurativas (o conhecimento das gerações mais novas suplanta rapidamente o das mais anciães por causa da velocidade e complexidade de informações tecnológicas).

Ruth Benedict também passa de estudos sobre configurações e padrões culturais de povos primitivos para reflexões sobre personalidades em nações contemporâneas. A obra mais conhecida neste sentido é seu estudo sobre os japoneses, O crisântemo e a espada (1972), elaborado em plena Segunda Guerra. Além de descrever a socialização entre pais, mães e filhos, ela também se impressiona com as diferentes formas de tratar as gerações nos Estados Unidos e no Japão, apelando para a valorização dos mais idosos e das crianças na sociedade japonesa em contraste com a supervalorização do adulto e de sua produtividade na sociedade americana.

Proliferam os estudos sobre caráter nacional. Na América Latina, autores de todos os países - notadamente mexicanos, argentinos, peruanos e brasileiros - dedicam-se a esta busca. No Brasil, a procura da autoridade geracional como reforço da nação é muito evidente em Gilberto Freyre (1969, 1979) e no grande número de autores que repetem as referências à importância histórica da família patriarcal (Holanda, 1988; Candido, 1951; Willems, 1953) na formação de uma capacidade de liderança capaz de integrar (muito mais que explorar) diversas culturas e estabelecer um grande domínio sobre uma rede familiar, repassando para as novas gerações estas capacidades, estes poderes (Scott, 2004).

O poder é sobre as gerações vindouras, androcêntrico e adultocêntrico, estende a lógica para o controle entre as gerações, associando alianças matrimoniais e estratégias de produção na lógica da família: uma família que Sérgio Buarque de Holanda (1988) percebe como impedimento - e não como base formadora - para o desenvolvimento do Estado. Para Gilberto Freyre, também: a historicidade impõe limites à possibilidade da sobrevivência deste modelo, quando, em Sobrados e mucambos, revela as fragilidades do conjunto, mostrando como as novas gerações vêm se capacitando 
(os bacharéis) para se tornarem jovens da cidade, desvinculando-se do poder dos senhores patriarcas rurais.

A nação não sustenta uma interpretação única, e a ideia de uma personalidade básica nacional, de um caráter nacional, tão bem resenhada na obra de Dante Moreira Leite (1969), inclui divergências internas sobre o que seria este "caráter".

Entre os autores americanos, Ralph Linton (1979) apropria-se das ideias de Mead e Benedict, criticando-as. Olha mais para a constituição da diversidade dentro das nações contemporâneas e a dificuldade de aplicar a ideia de "uma personalidade básica" para sociedades compostas por significativas diversidades internas. Advoga a noção estatística de personalidade modal para reconhecer outras personalidades simultaneamente presentes. Padrões de diferenciação identificáveis perpetuadas por relações entre gerações e famílias interagem em espaços diferentes na nação, resultando numa diversidade de personalidades.

Benedict, Mead e Linton terminam sendo ideólogos da família americana que estudam caminhos divergentes, com comparações externas e internas das práticas cotidianas da formação da personalidade. As individualidades vistas são circunscritas pelo social e pelo cultural; a transmissão de conhecimento de práticas realizada sobretudo entre pais e filhos que conformam às regras das coletividades nas quais participam. Nas abordagens adultocêntricas, o próprio país legitima-se simbolicamente na sintonia entre o que pai e mãe sabem e transmitem aos filhos, criando a realidade nacional da "pátria".

Em outra vertente da literatura de "integração, padronização e incorporação", predominam trabalhos ingleses, fusionados com ideias de integração francesas inspiradas em Van Gennep, Durkheim e Mauss.

Com os trabalhos etnográficos realizados por Malinowski, nos extensos territórios coloniais britânicos, Radcliffe-Brown (1982) nega a busca de origens e o enquadramento hierárquico no quadro de evolução. No entanto, faz isso sem recorrer à história. Defende a sociologia comparada; renega a ideia vaga de cultura; procura mecanismos pelos quais sociedades encontrem estabilidade numa lógica de estrutura funcional, detalhando como a organização de parentesco embasa as sociedades. Assim, dá a direção interpretativa para muitos estudos etnográficos na busca da coerência inter- 
na subjacente das instituições e relações sociais dos povos observados, independentemente da história. A estabilidade e a coerência buscadas por estes autores têm - na sua sustentação - um modelo familiar que privilegia a filiação, a experiência de ritos de passagem e a discussão de linhagens como promotores da unificação coletiva.

Radcliffe-Brown descreve com muito detalhe as relações entre as gerações com o pressuposto de estabilidade. Propõe a união entre gerações alternadas. Primeiro, declara que os conflitos entre gerações contíguas resultam do disciplinamento e ensino das regras, função que é dos pais e tios. A contrapartida desta relação encontra-se na relação entre avôs e netos: mais suave e permissiva. Assim, a extensão da relação entre as gerações perpetua o sentimento positivo de pertencimento ao grupo através da alternância harmonizadora de gerações. A descoberta de uma lógica funcional e estrutural dos povos colonizados dá armas para questionar visões preconceituosas de administradores coloniais, mas este lado de "resistência" da interpretação encontra mais ressonância posteriormente, entre autores que enxergam que a história permite a superação dos pressupostos sincrônicos de equilíbrio radcliffebrowniano. O estrutura-funcionalismo trata o povo como unido, independente dos registros históricos.

Na introdução ao Ciclo de desenvolvimento em grupos domésticos, Meyer Fortes (1958) forneceu outra contribuição da abordagem estrutura-funcionalista aos estudos de geração. O ciclo trata de mudanças geracionais sociais, não de idade ou biológicas. Enfoca a relação à posição de pessoas num grupo doméstico que opera numa lógica de formação $\rightarrow$ expansão $\rightarrow$ dispersão $\rightarrow$ substituição organizada coletivamente em torno das relações de pais e filhos na sequência da vida. O indivíduo tem sua vida "etária" construída em relação a sequências sociais domésticas, realizadas em ciclos repetidos em todas as sociedades passíveis de comparação. Boa parte dos estudos subsequentes sobre família e grupos domésticos faz referência, direta ou indiretamente, a esta sequência cíclica. A variedade entre grupos observados é acionada mais para reforçar a percepção da adequação do modelo do que para realçar especificidades históricas e particulares. Há uma estreita relação entre esta visão estrutural-funcionalista da sociologia comparada e a visão funcionalista de uma sociologia que se situa na história de sociedades ocidentais.

Uma terceira vertente da construção do discurso sobre a relação entre gerações e família ocorre entre sociólogos interessados em caracterizar famílias 
e gerações da sociedade ocidental contemporânea. Trabalham a relação entre funcionalidade e historicidade, ora realçando um lado, ora outro. Ao enfatizarem a história, a geração histórica toma precedência sobre a geração entre parentes, e os estudos realçam ocorrências históricas que marcam a vida de "coortes etárias". A referência é mais a crianças, jovens, adultos e idosos (categorias etárias) de que a filhos, pais, avós e netos (categorias relacionais).

A família se faz presente, mas é relegada a uma importância secundária à configuração histórica das relações sociais mais amplas. Muitos especialistas abordam crianças, jovens ou idosos "numa certa época" - geralmente a atual. Mannheim (1951) e Elias (1990) sistematizam um pensamento que privilegia os tempos históricos e a inserção de certas coortes de categorias etárias, nem desprezando, nem alçando ao destaque as relações familiares na constituição de gerações. Destacam a maneira diferente pela qual o mundo é vivido por pessoas de diferentes gerações ganha visibilidade.

Entre os autores que enfocam urbanização e modernização (Redfield, 1941; Winch, 1954; Park, 1951; Parsons \& Bales, 1955; Goode, 1964; Lewis, 1959), há referências crescentes, especialmente após a Segunda Guerra (Latham, 2000), há uma recuperação de uma sequenciação hierárquica na forma do modelo do continuum folk-urbano e de uma migração para a cidade com a diminuição do tamanho da família e da parentela, passando de uma família extensa para uma família conjugal. Do campo para a cidade, ou de países pobres para países ricos, estas transformações indicam um ingresso na desejada modernidade.

Recorre-se a uma imagem de "familismo tradicional", que trata o favorecimento das relações, intra e intergerações como instituídas no âmbito das relações de parentesco. O peso do tamanho da família diminui, reforçando as relações entre cônjuges, e permitindo investimentos em educação e outros traços da modernidade para as gerações mais novas. Os estudos de comunidade produzidos sobre os diversos pontos do continuum folk-urbano situam-se de acordo com esta sequência. Subjacente a esta atitude, está a ideia de que as famílias precisam se tornar mais funcionais, sistêmicas e socializadoras, que a família conjugal - ou nuclear - representa um avanço no caminho de modernidade.

Neste longo período caracterizado por discursos sobre família e gerações que realçam integração, padronização e incorporação, há uma idealização 
de uma socialização em conformidade com um modelo hegemônico no qual as identidades de povos, culturas e nações - mesmo descritas com detalhe e diversidade - convergem para formar uma ideologia que marca o pertencimento a um grupo ou a uma coletividade abrangente. $O$ modelo se apresenta de pelo menos duas formas, uma sincrônica, outra diacrônica. A primeira busca sistemas funcionais e instituições que criam um padrão geral de comportamento ou de organização que valorizem alguma forma consensual do grupo no qual as famílias e gerações estão inseridas. A segunda interpreta os movimentos históricos de urbanização e modernização por lentes que sugerem a replicabilidade de caminhos de desenvolvimento nos quais as transformações de famílias e gerações, desenvolvendo as suas devidas funções, apontam para uma chegada predefinida no modelo.

Trata-se de uma historicidade limitada pela adesão a uma perspectiva de otimismo gerada pela intensificação de sentimentos de pertencimento e de nacionalismos exacerbados por conflitos entre nações. Ao longo do período, isto ocorre cada vez mais numa confluência em torno da perspectiva de modernizar-se, intensificando o crescimento econômico, sistematizando a organização de planejamento, informação e burocracia, bem como situando todas as populações na esfera de influência do conjunto de nações vitoriosas no pós-guerra, dispostas a articularem uma nova direção do mundo. As famílias e as gerações descritas poucas vezes deixam de ser percebidas como instrumentos ao alcance deste modelo.

4. Modos de produção, contenção de pobreza

e planejamento reprodutivo (desigualdade)

A ênfase muda com o desencanto em relação aos modelos de desenvolvimento. Favorece quadros de interpretação que realçam "modos de produção, contenção de pobreza e planejamento reprodutivo". Esta visão crítica e dicotomizada das relações entre nações contrapõe os modelos capitalista e socialista de desenvolvimento dos anos 1950, até, simbolicamente, a queda do muro de Berlim.

Continua o aperfeiçoamento técnico e de planejamento, mas acrescenta uma percepção da fragilidade e limitada viabilidade dos modelos existentes na redução de pobreza e na descoberta de caminhos para uma melhoria da qualidade de vida. Resumindo: é o fim do otimismo sobre o modelo desenvolvimentista, instala-se um ambiente crítico, denunciador e de resistência. Dá realce à constante perpetuação de desigualda- 
des, mais de que à integração. É um mundo com famílias empobrecidas, atreladas a economias desfavoráveis, cada vez mais subdividas em gerações cujos interesses corporativos não respondem, necessariamente, a uma ideia de integração.

As famílias descritas são resistentes a poderes opressivos, reportam a estratégias de um ou outro segmento da população e se dividem em desigualdades internas, de gênero, de classe e de geração. $O$ feminismo explode os princípios androcêntricos de modelos familiares. Paralelamente, percebem-se relações intergeracionais permeadas por tensões e diferenças, com os filhos contestando o mundo forjado pelos pais e pelos pais dos pais. Prolifera a discussão sobre modos de produção e sobre trabalho como esferas que produzem desigualdades. Investiga-se a relação da esfera pública com as condições e as relações de trabalho. Descrevem-se estratégias de sobrevivência dos desfavorecidos. Questiona-se o conceito de trabalho produtivo como mascarando as contribuições de mulheres e outros familiares fora da população economicamente ativa. A ideia da reprodução da força de trabalho é reexaminado para valorizar o trabalho das mulheres na esfera doméstica. $E$, evidentemente, a maior inserção de mulheres na força de trabalho é mais um fator que permite repensar a importância de arranjos diversificados de famílias para as relações de poder entre homens e mulheres e entre avós, pais, filhos e netos.

Elabora-se uma ideia de desenvolvimento dependente que reconhece a impossibilidade histórica de países pobres trilharem os mesmos caminhos para cumprir o modelo hegemônico de crescimento econômico. A marginalidade e a exclusão mostram as dificuldades de discursos de integração funcional. $O$ avanço das tecnologias contraceptivas para promover "a transição demográfica" ocorre num ambiente subjacente de ameaça da "bomba populacional" proveniente da superpopulação nos países pobres. Diversos fatores proporcionam profundas modificações na composição etária e na organização de domicílios, famílias e gerações em cada país. O controle técnico de mortalidade e de reprodução abre mais espaços para muIheres, com a sua maior longevidade e associação biológica e social com nascimentos e cuidados dos outros. Também abrem-se espaços para realçar diferentes formas de viver a individualidade e de perceber distinções entre as gerações.

A importância da questão de trabalho e de relações de produção como estruturas de poder que promovem desigualdades e subordinações marca 
profundamente a perspectiva predominante neste período. A literatura marxista crítica floresce. Assim, sistematiza-se a percepção de modos de produção múltiplos; modos alternativos de produção articulam-se e se subordinam aos modos dominantes. Dois destes modos alternativos são teorias sobre famílias e gerações: o modo de produção camponesa e o modo de produção doméstico.

A teoria da economia camponesa de Chayanov (1966) e Woortmann (2001) é redescoberta. Esta postula uma centralidade das demandas de consumo e percepções do desgaste cotidiano (drudgery) proveniente do trabalho da família camponesa, que elabora suas atividades de produção de acordo com as mudanças de composição etária do grupo ao longo do ciclo doméstico. Internamente, reforça uma perspectiva de gerações interrelacionadas de maneira solidária nas façanhas do grupo. Em outro nível de interpretação, o modo de produção doméstico, segundo a perspectiva dinâmica e crítica do marxismo, denota uma "resistência" que serve de defesa entre desiguais. Quando contraposta ao modo de produção capitalista com os seus objetivos de lucro, a família de um segmento camponês da população - com gerações unidas em torno da produção - revela-se contestatária em sua luta pela sobrevivência social.

O grupo doméstico e a família - partes centrais de estruturas de produção são dissecados por autores de diversos horizontes, mostrando explorações de mulheres por homens, de gerações mais novas por gerações mais velhas etc. Marshall Sahlins (1972) foca as limitações inerentes na exploração de trabalho de familiares de gerações mais novas nas praticas de distribuição e sucessão entre grupos tribais. Nas coletâneas de antropologia econômica, Carvalho (1978) e Pouillon (1978) reúnem estudos que analisam as relações internas de gerações e gênero observando desigualdades na distribuição de benefícios sociais e econômicos de produção, chegando à proposta de um "modo de produção de linhagem" que se sustenta na manutenção de poder dos mais velhos sobre os mais novos através das negociações de trocas materiais e sociais que circundam os arranjos matrimoniais (Rey, 1978). Estes trabalhos - explicitamente ou não - devem bastante às observações de Claude Lévi-Strauss (1981) que incorporaram as relações sociais decorrentes das alianças matrimoniais para questionar um modelo simplório de família conjugal ou nuclear. O uso exagerado do modelo nuclear restringe a percepção às relações de filiação ou linhagem, e Lévi-Strauss insiste na importância de se atinar para as relações entre componentes internos mais complexos da família, abalando a visão unificada e solidária. 
Meillasoux (1997) inspira-se neste questionamento para articular a incorporação de desigualdades entre gênero e gerações no contexto de relações internacionais consciente da mobilidade e de contatos entre nações e povos. Propõe um quadro interpretativo de "Estruturas alimentares de parentesco", no qual a lógica da distribuição de produção dentro da família é destrinchada entre produtores (adultos) e não produtores (crianças e idosos). A inserção destes em redes de migrações revela o quanto o modo de produção capitalista (por onde destinam os migrantes jovens adultos) consegue aproveitar-se do trabalho de produtores realizado em famílias fortemente organizadas em torno da produção doméstica - sobretudo em seus países de origem. Estes - países e famílias - são "celeiros", produzem futuros produtores e cuidam dos trabalhadores quando afastados da produção. Mesmo que os migrantes de retorno consigam juntar alguns recursos, são enfraquecidos pelo desgaste decorrente do trabalho intensivo e pelo avanço da idade enquanto imigrantes em países alheios. As linhas de desigualdade passam pela idade e relação de parentesco de países e grupos na "periferia", no "Sul", enfim, nos países pobres, nas relações entre nações.

As abordagens marxistas não estão sozinhas nesta percepção de desigualdades calcadas em domesticidade. Georges Balandier (1977) chama a atenção ao fato que gênero é uma desigualdade que não se supera ao longo da vida, enquanto a idade constitui uma subordinação transitória e superável, ambos sendo sensíveis às políticas e estruturas de poder de países em desenvolvimento. Instituições pan-nacionais como a Comissão Econômica para América Latina (Cepal), ao procurarem entender as maneiras de lidar com a crescente pobreza nos países da região, propagam uma visão centro-periferia que discute a informalidade da economia, reconhecendo a importância de lógicas familiares de produção, contrapostas às relações formais. Famílias desenvolvem estratégias de sobrevivência que aproveitam diversas fontes para se defenderem de economias predadoras. Em todas estas versões, a família, por ser variada e ter uma lógica própria, é resistente.

A ideia de "marginalização" é amplamente debatida, em argumentos sobre a funcionalidade de populações "excedentes", bem como na criação de desvios e divergências de padrões de incorporação plena nos "benefícios" do crescimento econômico. As populações "marginalizadas" incluem adultos desempregados e empobrecidos, jovens, idosos e mulheres. Isto abre o caminho para gerações também servirem de mote para discussão de desigualdades, como se observará adiante. 
A obra de Pierre Bourdieu percebe famílias, gerações e poder na diversidade temática deste período realçador de desigualdades e de resistências. Elabora uma teoria da prática (1996), na qual esboça uma articulação entre poder, desigualdade e simbolismo ao estudar "campos" específicos que informam linguagens e práticas que constituem um habitus para a estruturação dos próprios campos. Os "campos" que o sociólogo estuda são fragmentos - pedaços definidos aleatoriamente, de acordo com interesses específicos de investigação e compreensão forjados na observação e discurso sobre a prática social. Nestes campos fragmentados, mostra uma sensibilidade grande a gênero, geração e classe.

No estudo "A dominação masculina", Bourdieu (1999) enfoca as relações de poder entre homens e mulheres e elabora o conceito de violência simbólica, que desvenda como os subordinados frequentemente, sem perceber, reforçam as próprias estruturas que os subordinam. 0 discurso da desigualdade, sempre presente na obra de Bourdieu, não é um discurso isolado. Permeia as abordagens, indo para assuntos além da conceitualização de família e de geração. Se o "desigual subordinado" está sujeito a amarras que ele mal consegue enxergar, a teoria da prática reconhece uma possibilidade, limitada pela tendência para a perpetuação dos campos, de transformar as estruturas através de praticas contra-hegemônicas, ou de resistência.

Além de o gênero ser um dos campos mais transparentemente hierarquizados, percebe-se uma ascensão - não uma inversão - do poder das mulheres em relação ao dos homens. As autoras feministas rebelam-se contra uma idealização da família solidária por conta do que esta ideia esconde da exploração de mulheres e da falsa idealização manipulada do papel "geracional" de maternidade. Trazem à tona discussões sobre o corpo, o privado, a socialização, o trabalho doméstico e o cotidiano como contextos de realização de subordinação nos quais as mulheres denunciam práticas repetidas de maltrato e de subvalorização que requerem ações de combate e resistência.

Implode a pressuposição de união solidária de famílias e gerações. Uma das manifestações desta implosão ocorre nos questionamentos da noção de "papéis" sociais por causa das implicações "roteirizadas" que ela traz para uma interpretação sociológica. Para se afastarem de uma pressuposição da inevitabilidade de alguns processos sociais, diminui a referência às vidas individuais e domésticas como "ciclos", substituindo este termo pela mais flexível e variável noção de cursos de vida, uma discussão muito bem elaborada em Müller (2008) e Hareven (1978). 
A descoberta e visibilidade de mecanismos do reforço da desigualdade tornam-se uma bandeira de luta para a superação da pobreza e da marginalização econômica e social, no sentido de se encontrar caminhos possíveis de construção societária. Os questionamentos se manifestam numa descoberta de miríades de contrapoderes: poderes difusos foucaultianos, astúcias decertauianos, resistências pelas armas dos fracos e de economias morais camponesas de James Scott, representações do palco e dos bastidores de Goffmann, operação de modos de produção alternativas marxianas (domésticas, asiáticas, camponesas etc.) - todos a questionarem lógicas de dominação.

Em todos estes casos, há, de alguma forma, um enaltecimento à reação contra as desigualdades e a sugestão da necessidade de encontrar uma solução de resistência no familiar e no cotidiano, mesmo se de limitadas dimensões. Nas relações interpessoais e na intimidade que afetam a vivência de laços conjugais que não giram em torno de filhos, Giddens (1993) revela uma busca de relacionamentos "puros". Os parceiros procuram satisfação individual na mutualidade, desfazendo a relação quando um ou outro se desencanta com a relação. A individualidade e o sujeito encontram espaços inusitados para a compreensão de famílias e gerações. Neste ambiente, a discussão da família integradora e solidária desmancha-se no ar (como diria Berman); a família e, mais timidamente, as gerações ganham a vez como bastiões de resistência.

A atenção específica às gerações históricas e etárias - a infância, a juventude, a adultez e a velhice - cresce, mas não assume as dimensões autônomas que tomará posteriormente. A juventude merece atenção por ser resistente e contestadora, seja por sua adesão a ações que revelam consciência moral da necessidade de promover mudanças na sociedade, seja pela sua adoção de comportamentos entendidos por uma ótica de divergência ou contestação, como, por exemplo, em Eisenstadt (1976). Com alguma frequência, esta atenção se imbrica com outras preocupações, sobretudo à de transição demográfica em que o prolongamento da vida pela melhora das condições sanitárias e médicas vem acompanhado pelo temor da perpetuação de altas taxas de fecundidade concentradas nas populações dos países mais pobres.

Países em desenvolvimento com populações jovens e numerosas são percebidas como politicamente voláteis pelos países centrais, e estes países, visando à continuação da sua hegemonia, exportam o seu medo com pacotes de planejamento familiar, repletos de ações de contenção da popula- 
ção com base de controle da reprodução. Promovem esterilizações e medidas de prevenção de gravidez. Mulheres em idade reprodutiva, sobretudo as jovens, ganham acesso a um conhecimento que reforça modificações no seu poder sobre o seu corpo e a sua inserção social, em relação às demandas de cuidados dentro da família. Rapazes jovens, por outro lado, são associados ao desemprego e à marginalização. No Brasil, esta dupla marginalização (do mercado de trabalho e do poder doméstico) que recai sobre homens jovens e adultos foi muito bem examinada por Klaas Woortmann (1987), em seu estudo sobre a Bahia dos anos 1970.

Bourdieu (1983) capta as múltiplas preocupações contidas no crescente número de estudos sobre juventude, alertando que "A juventude é apenas uma palavra". Reporta à polissemia do termo para lidar com a sensibilidade de suas diversas implicações para a qualidade das interpretações desta geração que, sem reificar o termo em si, merecem abordar as relações de poder e as subjetividades que o caracterizam.

Os estudos dos mais idosos, neste período, são relativamente escassos, mas sempre fazem alguma referência à maior longevidade para depois descreverem a memória e as condições de vida. Sabe-se que o investimento na transição demográfica leva a um "envelhecimento populacional", mas este grupo etário, como geração, ganha mais realce quando vira "problema" a ser administrada pelos planejadores da previdência dos países centrais, enfrentando um superpovoamento das gerações dependentes mais velhas e uma sobrecarga na tributação dos trabalhadores ativos.

Dois trabalhos enfocando a família no início dos anos 1990 - um do Brasil e outro da França - revelam o quanto andou a relação entre família e gerações. Ao assumir as ideias tão divulgadas de estruturas domésticas maleáveis e capazes de oferecer formas de resistência elaboradas pela população em resposta às transformações societárias para América Latina, Goldani (1993) e Jelin (1994) encaram uma campanha de combate aberto contra a noção da desestruturação da família. Insistem que o crescimento de famílias monoparentais (casais sem filhos) e pessoas morando sozinhas não evidencia desestruturação. Muito conscientes de processos demográficos, um dos pontos nodais é de como a longevidade e a queda da fecundidade têm permitido uma vivência de relações entre gerações bem mais complexa e variada que antes. A diminuição do tempo dedicado à educação intensiva dos filhos e a ampliação do tempo de vivência intergeracional fazem parte de uma realidade de diversidade de arranjos 
familiares que, longe de responderem a uma organização cíclica, também desafiam a noção de seguirem "cursos". A família, nesta ótica, aproveita a sua flexibilidade para se perpetuar, proporcionando uma multiplicidade de oportunidades de situações vividas, pouco redutíveis a simples ciclos, cursos, ou mesmo visões de saudosismo de famílias patriarcais integradoras.

No sucinto A propos de la famille comme catégorie realisée, Bourdieu (1993), sempre muito crítico a violências simbólicas, alerta sobre o fato de a categoria "família" sempre carregar consigo diversos significados subjacentes que podem escapar ao observador que não está atento às desigualdades imbricadas no termo. Bourdieu usa a sua teoria da prática para botar mais lenha no desmonte da perspectiva da família solidária e indivisa. Consagra a compreensão da família como uma estrutura de poder permeada por hierarquias instituídas que oferecem espaços tanto para resistências como para a vivência de subjetividades diversas. Ou, em forma mais abreviada: é importante desvelar os componentes de desigualdades de gênero, de geração e de classe para se entender a família.

\section{Direito à diversidade (fragmentação)}

Na globalização atual, o discurso de "direito à diversidade" privilegia um favorecimento de múltiplas reivindicações de grupos vistos como possuidores de direitos por terem uma maneira de ser ou uma cultura própria. Sem a dicotomia entre o mundo socialista e capitalista, amplia o poder político de conferências internacionais centradas em interesses de grupos específicos. Simboliza um mundo democratizado e fragmentado entre demandantes de direitos expressos como sendo "multiculturais". Isto, decomposto nas suas muitas partes constituintes, tem implicações para a família e para as gerações.

Espaços novos e antigos abrem e alargam-se em torno da discussão de papéis individuais, psicológicos e ideológicos na família, e questões sobre políticas públicas, reprodução, gênero e sexualidade se tornam temas importantes, forjados agora num linguajar de direitos internacionais e cooperação para a criação de uma diversidade legítima sob a vigilância da ordem global. Procuram-se direitos, definidos e (controlados) por meio de movimentos capazes de colocar holofotes sobre as demandas dos seus participantes, e a família, devido à sua própria diversidade, se torna uma arena para a negociação e 
realização desses direitos, muito mais do que um sujeito de movimentos ou de investigação próprios (Scott, 2004: 70).

A individualidade reafirma-se na escolha dos pertencimentos. Configurase um discurso de reelaboração permanente de "moralidades não canônicas" como candidatos legítimos a direitos coletivos (Ávila et alii, 2005; Scott, 2005). A família flexível e plural (Vaitsman, 1994) foge de categorizações fechadas e permite interseções diversas, ganhando status de simplesmente mais um elemento da organização social, dissolúvel e remontável, e muito menos "a base de tudo". Desta maneira, intensifica a percepção da importância "de famílias", mais do que "da família", bem como de movimentos diversificados que apoiam o pluralismo de demandas de gênero e de geração, por sua particularidade, e não por fazerem parte de grupos familiares.

Ao lado das gerações, os direitos da infância, da juventude e dos idosos - com estatutos e regulamentações calcados em acordos e cooperações internacionais - ganham prioridade como grupos de demandas específicas, independentemente de serem componentes "da família". Defensores articulam-se para lidar com as categorias etárias geracionais nos seus contextos específicos, procurando acordos e metas para defender os grupos. São contextos políticos amplos - mais do que simplesmente componentes de famílias e grupos de parentesco - que caracterizam o tratamento destas gerações.

Se o combate à mortalidade infantil exige pactos globais amplos para que os países encontrem condições de defender a primeira infância, a localização do combate vai além de estímulos às famílias, às mães e aos pais. Situam-se em medidas específicas de promoção de condições ambientais, de saneamento e de atendimento à primeira infância. Para crianças e adolescentes, elaboram-se estatutos de proteção para evitar exploração sexual, de trabalho e tráfico, novamente todos inseridos em redes de aplicação de acordos internacionais com forte participação de movimentos sociais e de organizações mobilizadas contra tal exploração e abandono e a favor de práticas saudáveis e protagonismos para crianças e jovens. Contribui para a criação de uma imagem de família progressivamente mais fragmentada, implicitamente considerada incapaz de cuidar de sua própria prole. Forma-se uma "geração" alvo de políticas públicas específicas, explicitando ainda mais as suas culturas (como grupos etários) e os direitos que os acometem como cidadãos.

A imagem fragmentada da família não releva um pleno desprezo pela instituição, pois as medidas estimuladas e promovidas envolvem, entre muitas 
outras coisas, a recuperação de laços familiares e a criação de espaços que permitam que as famílias possam investir na educação e socialização "adequada" dos filhos. Mas a família é mais um elemento, não precisando ser o locus político privilegiado para esta defesa. Para o mundo globalizado, a geração histórica etária é mais situável dentro das lógicas nacionais do que a geração familiar ou de parentesco. Por exemplo: a valorização de "culturas juvenis" é um mecanismo eficiente de realce de geração acima da família com a qual se articula limitadamente. E a multivocalidade juvenil mostra a variabilidade resultante (Alvim \& Gouveia, 2006).

Quando se trata de adolescentes e jovens na problematização específica da geração, há uma divisão de discursos sobre jovens do sexo masculino e do sexo feminino. Além das tentativas de identificar fatores de focalizar a vida familiar ou doméstica relacionados com a transição de adolescência e juventude para a adultez (discutida mais adiante), ressalta-se um mundo feminino de reprodução e um mundo masculino de produção, marginalização e violência. Tais mundos são entendidos parcialmente em função de conflitos geracionais e estratégias para ganhar "liberdade" e "autonomia" como componentes de uma "cultura juvenil".

No mundo feminino de reprodução - com mais e mais mães submetendose à esterilização em idade bastante jovem -, as mulheres adultas estão tendo menos filhos. Obviamente, a proporção relativa de mães adolescentes aumenta. Alarmados, os órgãos oficiais de saúde e as instituições escolares esforçam-se para controlar a reprodução feminina e a sexualidade, abrindo um campo rico para a aplicação da psicologia de adolescentes e teorias de transição repletas de ausências "familiares" - ausências paternas, falhas maternas e sociais em geral. O respaldo para esta atenção vem de instituições internacionais, governamentais ou não - Organização Mundial de Saúde (OMS), Organização Pan-Americana de Saúde (Opas), Planned Parenthood Association (PPA), Fundação Ford, Fundação MacArthur etc.

No mundo masculino de produção, marginalização e violência, a atenção recai na concentração do desemprego entre os jovens e o seu envolvimento em roubos, assaltos, narcotráfico, torcidas organizadas truculentas, e demais tipos de manifestação com base em valores de agressividade, contravenção e criminalidade (Fernandiz \& Feixa, 2005). Mais uma vez, ressalta-se a ausência ou falha das famílias lidarem com os filhos num mundo de oportunidades limitadas. Estudos da Unesco (cf. Waiselfisz, 2000) procuram saídas ou formas de combater este aspecto da vida juvenil, na esperança de 
baixar os índices de mortalidade violenta que tanto afeta a este segmento. Os idosos - mais em evidência como geração por causa da transição demográfica e do envelhecimento populacional - ganham estatuto específico de defesa de seus direitos de inclusão, previdência, saúde, prevenção à violência e à exploração. Organizam-se tanto em grupos conscientemente dirigidos em defesa destes direitos, como em grupos de convivência e em programas de ensino e qualificação que visam ao melhor aproveitamento da longevidade.

A partir de uma perspectiva de parentesco e gerações elaborado por Gilberto Velho (1986) nos anos 1980, o estudo marcante de Lins de Barros (1987) mostra a capacidade de os avós - e especialmente as avós - serem reforçadores de laços de parentesco e de família, assegurando comunicação entre cinco gerações.

Em outro estudo, Berquó (1986) descreve como idosas passam a viver sozinhas enquanto envelhecem, vivendo a pirâmide de solidão, diferentemente dos homens, que costumam casar-se novamente. Se estes estudos revelam uma aguda consciência da articulação entre a geração mais velha e as consequências na esfera dos arranjos conjugais e familiares, diversos estudos posteriores (notadamente os de Berquó, 1999; Camarano, 1999; Lins de Barros 2006; FIBGE, 2002; Debert, 1999; Britto da Motta, 2004, 1998a, 1998b; Scott, 2009) revelam uma autonomização desta geração. Não se cultua uma "cultura senil" da mesma forma que se cultua uma "cultura juvenil". Mesmo assim há uma juvenescimento desta geração, do seu envolvimento em atividades de divertimento e de sua valorização própria. A extensão de longevidade permite uma diversidade de maneiras de autopercepção e de relação com os outros. É uma geração que protagoniza uma cidadania própria, com formas de sociabilização própria e destaque em políticas públicas, como destaca Lins de Barros (2006: 11-15). Mais uma vez, a família não some na compreensão do cotidiano desta geração, mas ela não é o foco privilegiado de ênfase.

Para entender as gerações, passa-se por conceitos envolvendo ciclos, cursos, trajetórias e transições, para desembocar numa valorização de direitos e cidadanias onde o reconhecimento da diversidade ocorre numa separação analítica parcial entre a ideia de geração e de família. Referir-se à passagem por gerações como cíclico sugere a repetição de processos sociais; referir-se como curso de vida flexibiliza limitadamente, deixando mais margem a eventualidades e ao aleatório; referir-se como trajetória instila uma 
força de subjetividade e decisão individual na escolha da direção. Neste caminho todo, as próprias famílias se pluralizam e se diversificam, favorecendo um uso mais pontual e específico da compreensão de sua relação com as maneiras em que as gerações se apresentam como grupos demandantes de atenção independente no mundo global.

Müller (2008: 145-159) faz uma revisão esclarecedora de algumas obras internacionais chaves das ideias de curso de vida e de transição (idem: 254283). Articula a continuação de uma percepção da importância cronológica de indivíduos em grupos etários, com a organização de grupos domésticos e familiares, e a subjetividade "descronologizante". Sua adesão (assim como a da equipe de pesquisa de Hansen, 2008) às ideias de tempos sociais de eventos mais atrelados a conjunturas vitais dá destaque à abordagem de Jennifer Johnson-Hanks (2004), que se inspira em Bourdieu para elaborar a compreensão de diferentes contextos de ação:

É preciso, por exemplo, deter-se no caráter mais subjetivo desta transição à adultez. Jennifer Johnson-Hanks (2002) chama a atenção para a extrema variabilidade dos eventos da vida (no tempo, no espaço, mas também em ordem e sincronização). Por causa desta variabilidade, a autora sugere que nos afastemos da reflexão sobre os eventos de transição como sendo o que organiza a vida dos indivíduos. Em lugar disto, a autora propõe o foco nas instituições e aspirações, reconhecendo que estas aspirações são múltiplas, mutáveis e aplicadas numa variedade de enquadramentos temporais (Müller 2008: 259).

A compreensão de gerações, sem perder um substrato familiar, apresentase como organizada em torno da subjetividade, de noções de tempo e de configurações históricas específicas. Em seu estudo sensível à variabilidade juvenil da vivência temporal, Franch Gutierrez (2008) revela singularidades, riscos, incertezas e configurações contextuais específicas nas trajetórias, de acordo com as escolhas e as oportunidades dos jovens. Ao elaborar uma discussão sobre o debate em torno da noção do tempo, Franch Gutierrez evoca uma pletora de autores, entre os quais Leccardi (2005) é quem mais claramente respalda as abordagens que dão importância às mudanças na percepção de tempos biográficos individuais relacionados com transformações bastante imprevisíveis do curso de vida. As configurações e os contextos históricos específicos da vivência de gerações encontram em Norberto Elias (1990) um expoente muito sensível a transformações histó- 
ricas e subjetividade. Os processos de sociogênese da configuração social e da psicogênese do indivíduo se entrelaçam para formar conceitos de transição, cursos e trajetórias sobre a inserção de pessoas em realidades locais no mundo interconectado. O estudo de Maurício Tavares sobre jovens no sertão de Pernambuco (2009) sistematiza a aplicação destas ideias ao estudo contemporâneo de gerações.

Há também outro lado da globalização e reinterpretação de relações entre gerações que reporta à interconectividade entre redes de parentesco que vinculam populações que residem em duas ou mais nações. A mobilidade de populações entre países é uma constante em todos os períodos discutidos aqui, mas as características dos contatos entre pessoas nas nações de destinos e de origem mudam. Atualmente, a mobilidade ocorre apesar das grandes barreiras legais erigidas contra boa parte da mobilidade espacial. Na falta de tal regulamentação internacional, a mobilidade seria muito maior.

A ampliação da presença de populações emigradas de países em desenvolvimento nos países centrais na era de viagens fáceis e de informática que assegura comunicação imediata, a quase qualquer hora, contribui para a maneira em que mobilidade é tratada como assunto de geração e de família. Neste percurso, as relações entre gerações em redes de parentesco realçam o valor da "família" como símbolo de solidariedade e unificação, ainda mais ampliada quando pensada como parte de uma rede capaz de ser acionada para conseguir permissão para atravessar fronteiras que, por quaisquer outras razões, seriam fechadas para migrantes.

A reunificação familiar, na Europa e, em menor grau, nos Estados Unidos, é um idioma político "universalista" que abre oportunidades para muitos migrantes. De certa maneira, há um aprofundamento de ideias de gerações compactuadas em famílias para lidar com a mobilidade, elaborado por Meillasoux para africanos que viajam para a Europa (1997) e por Arizpe (1981) sobre mexicanos que se dirigem para a cidade do México e para os Estados Unidos.

Diversos estudos nas coletâneas de CNPD (2001), Martes e Fleischer (2003) e Fonseca (2009), e nas partes de "famílias transnacionais" e "migrações internacionais" dos Anais da 54a Reunião da International Society of Americanistas (2009) mostram como os laços entre diferentes gerações de famílias internacionalizadas contribuem para superar os impedimentos à mobilidade, seja através de cuidados de netos, da chamada de aparenta- 
das, de arranjos de permissões e de espaços de residir, do uso de meios de comunicação virtual ou de muitas outras ações que servem para englobar as pessoas distanciadas espacialmente numa família de alto valor simbólico para a unificação do grupo que traspassa as fronteiras de uma nação.

Apesar da migração ser realizada preferencialmente por grupos de jovens e de jovens adultos, não é este aspecto de geração etária nem o aspecto de geração histórica, e sim o aspecto de geração de família e de parentesco que se destaca nestas análises.

6. Família, gerações:

Articulações e abordagens em transformação

Ao longo deste trabalho, apresentaram-se abordagens sobre gênero e família com caracterizações das suas ênfases selecionadas num campo muito vasto. Fundamental é reconhecer que a própria polissemia das noções de gênero e geração deu margem a mudanças históricas nas ênfases no uso destas noções na articulação com as estruturas de poder entre nações. Entre outros elementos possíveis, deu-se destaque à mobilidade como tema que se insere na construção de imagens de populações que compõem as nações.

A articulação entre gerações e famílias no período de enquadramento hierárquico promoveu usos dos termos para reforçar a percepção de uma ordem idealizada e a-histórica de evolução e hierarquização. Famílias foram compreendidas em tipologias nas quais a geração foi tratada como pouco mais que os meios para a formação de regras para a inclusão em grupos que cabiam na tipologia. Mobilidade e migração em populações concretas foram bastante ofuscadas nestas versões de compreensão.

Com o advento da intensificação de interpretações históricas e abordagens informadas por contato direto com populações colonizadas num mundo de conflitos e de reordenações das hierarquias de relações entre nações, os estudiosos encontraram maneiras de enxergar a família como a base de tudo na construção reificada da nação ou na cultura de algum povo estudado. Neste período de "integração, padronização e incorporação", afinados com o modelo de desenvolvimento americano, os estudos de personalidade realçam mecanismos de socialização, privilegiando a busca de mecanismos de produzir desde culturas específicas até nações inteiras; estudos estrutura-funcionalistas antropológicos buscam as suas funções integradoras e estabilizadoras; e estudos de modernização receitam uma passagem 
de funcionalidades diferentes de famílias que passam de rurais - grandes e numerosas - para urbanas - pequenas e nucleares - na transformação de nações destinadas a se desenvolverem.

De uma maneira paralela, a abordagem das gerações se historiciza ao longo do período, passando de, sobretudo, sincronicamente integradora e funcional na construção das imagens de cada povo ou nação estudado, para reveladora de mudanças provenientes da modernização e dos avanços de tecnologia. As mudanças na socialização das relações intergeracionais fornecem a chave interpretativa para o questionamento vindouro da idealização da família nuclear.

Com o desencanto do modelo hegemônico de desenvolvimento capitalista americano, o olhar dos estudiosos de família e gerações passa para a perceber desigualdades nos "modos de produção, programas de contenção de pobreza e planejamento reprodutivo". O registro de diferenças desiguais desarticula a versão da imagem de famílias integradoras e inicia uma frente discursiva que enaltece a resistência e a busca de caminhos alternativos, realizada ora por gerações específicas, ora por famílias inseridas em segmentos específicos da população em contenção ao Estado e aos grupos dominantes.

Neste período, desempacotar a família nas suas partes constituintes permite denunciar desigualdades hierárquicas inerentes a maneira em que a aplicação dos modelos históricos de desenvolvimento intensifica estas e outras desigualdades. A atenção a modos de produção diversos é uma maneira de desempacotar que cria uma intensificação da compreensão de como família e gerações operam como explorados e como exploradores.

A identificação de estratégias de trabalho que defendem as famílias contra o empobrecimento é uma forma de inseri-las no discurso de resistência às desigualdades. A ascensão do feminismo legitima outro discurso de denúncia de desigualdades calcada fortemente nas relações familiares e a aplicação de tecnologias de planejamento familiar traz a contrapartida de maior liberdade e autonomia feminina para decisões sobre a quantidade da prole e a qualidade da ampliação da sua inserção no mercado de trabalho.

Nesta situação de crítica exacerbada, ocorre um novo realce de atenção a gerações históricas de contenção (cf. a geração de 1968) e de gerações como 
grupos etários - crianças, jovens, adultos, idosos - indo além dos aspectos integradores de gerações de família e de parentesco.

Não é raro ouvir dos defensores de perspectivas que se centram em geração ou em gênero, que o argumento que coloca a família no centro seja atravessado por intenções conservadoras, condenáveis numa época de enaltecimento do combate e resistência às desigualdades.

Há uma mudança significativa no tom das interpretações com o desencadeamento de processos de democratização e com o fim do bloco socialista, quando a percepção das desigualdades encontra um discurso de direito à diversidade que a associa a um mundo global, interconectado e aparentando mais sensibilidade a culturas e maneiras de ser mais diversas. Mesmo não deixando de apresentar desigualdades, a família, segmentada e fragmentada, ganha mais valorização no plural como famílias, menos amarradas a qualquer modelo idealizado, e prezadas por sua própria flexibilidade.

A diversidade parte de um discurso de multiculturalidade, manifesta-se num novo auge de interesse em recortes geracionais de grupos etários num mundo perceptível em configurações espaciais e sociais diversas. A subjetividade, no seu contexto social, os indivíduos inseridos em estruturas estruturantes ou em configurações sujeitas a articulação de sociogênese e psicogênese dão espaço a diferentes interpretações. Valorizam-se fronteiras móveis onde se destaca a pessoa cujo pertencimento ao grupo lhe dá direito a uma maneira própria de ser, defendida por políticas de Estado, reforçada por movimentos e acordos internacionais.

Volta-se à ambiguidade de Zedmundo, no conto de Mia Couto, citado na epígrafe deste trabalho. Couto conduz o leitor a um mundo de sentimentos construídos em relações sociais de gênero e geração, sem fazer referência à historicidade.

Na discussão das abordagens na literatura sobre família e geração e as suas mudanças históricas, percebeu-se que a articulação de diferentes questões associadas às relações entre nações reforçou certos significados destas noções, sem preterir a continuidade de referências à polissemia dos dois termos. Atrelado a gerações de família e parentesco que ele julga restritivas, Zedmundo procura uma subjetividade que está exatamente no lugar que ele julgava que estava sendo impedida, nas próprias relações de geração de parentesco e de família. Em qualquer período da literatura des- 
crita, este discurso teria validade, mas foi possível ver que as articulações históricas e espaciais do discurso favoreceram uma fala de cobrança de subjetividade e individualidade no mundo contemporâneo.

Uma leitura linear da periodização descrita nestas páginas pode desvendar alguma coisa sobre a história cronológica, mas feriria o objetivo básico do trabalho, qual seja o de demonstrar que se faz recurso à flexibilidade das categorias de família e de gênero ao longo do tempo para articular percepções distintas forjadas em macroestruturas de poder. Mobilidades espaciais e temporais contribuem para constantemente criar novas configurações que informam possibilidades de ênfases diferenciadas.

Famílias são compostas de gênero, geração, conjugalidade, sentimentos de pertencimento, ideias de corresidência, cooperação solidária, autoridade, afeto e subjetividade, entre outras coisas. Gerações são compostas de pessoas entrelaçadas hierarquicamente por redes de parentesco e família, por pessoas ligadas por pertencerem a categorias etárias e por pessoas cuja referência temporal é algum evento ou ambiente histórico que unifica muitas pessoas geralmente em referência a algum evento exterior à idade e ao parentesco.

De certa maneira, os usos, em horas diferentes, de ideias de ciclos, de cursos e de trajetórias, ao discutir gerações, reflete uma ascensão atual de subjetividades, configurações fragmentadas e de noções diversas de tempo numa articulação longa e variada de ideias forjadas de acordo com a polissemia e a mobilidade dos objetos em investigação.

Abstract: A selected review of national and international literature about family and generations shows how changes in power relations among nations favor different historical emphases on hierachy, solidarity, inequality and rights. When family is referred to as a basis for national or group identities, it does so from the perspective of "hierarchical inclusion" and of "integration, patterning and incorporation". Evolutionism, personality and culture, structural-functionalism, urbanization and modernization, emphasize hierarchies, unity and stability, restricting generations to a similar agenda. When family is referred to as a means of resistence against inequality, it does so in reference to "modes of production, reduction of poverty and reproductive planning" and leaves more space to discuss generations as unequal an separate age groups with their own interests. This approach intensifies with the emphasis on plurality and 
fragmentation of families in a global world, permitting the treatment of generations as groups with equal permitindo que gerações recebam tratamento como grupos com igual rights to diversity with their own cultures, partially dissociated from families. How migration and mobility are related to the ambiguities and polissemy of inter-generational relations and family. Key words: families, generations, polissemy, mobility, nations, power.

\section{Referências citadas}

Alvim, Rosilene \& GouveIA, Patrícia (orgs) (2006). Juventude anos 90: Conceitos, imagens, contextos, Rio de Janeiro: Contra capa/Gestão Comunitária: Instituto de Investigação e Ação Social.

ARIZPE, Lourdes (1981). "The rural exodus in Mexico and mexican migration to the United States", International Migration Review, Vol. 15, n. 4 (Winter), pp. 626-649.

Ávila, Maria Betânia; Portella, Ana Paula \& Ferreira, Verônica (orgs) (2005). Novas legalidades e democratização da vida social: Família, sexualidade e aborto, Rio de Janeiro: Garamond.

Balandier, Georges (1977). Antropológicas, São Paulo: Cultrix.

Benedict, Ruth (1934). Padrões de cultura, Lisboa: Livros do Brasil.

— (1972). O crisântemo e a espada, Perspectiva: São Paulo.

Berquó, Elza (1986). "Pirâmide de solidão?", in Anais do V Encontro Nacional de Estudos Populacionais, Abep.

- (1999). "Considerações sobre o envelhecimento da população no Brasil", in A. L. Neri \& G. G. Debert (orgs), Velhice e sociedade, "Coleção Vivaidade", Campinas: Papirus.

Bourdieu, Pierre (1996). Razões práticas: Sobre a teoria da ação. Campinas: Papirus.

- (1993). "A propos de la famille comme catégorie realisée", Actes de la Recherche en Science Sociales, 100, Paris. 
- (1999). A dominação masculina, Rio de Janeiro: Bertrand do Brasil.

- (1983). "A 'Juventude' é apenas uma palavra", in idem, Questões de sociologia, Rio de Janeiro: Marco Zero, pp. 112-121.

BRITTO DA MotTA, Alda (2004). "Gênero, idade e gerações: Introdução", Cadernos $\mathrm{CRH}$, Vol. 17, n. 42, Salvador: Centro de Recursos Humanos/UFBA, pp. 349-357.

— (1998a). "Introdução: Gênero, família e fases do ciclo de vida", Cadernos $C R H$, n. 1, Salvador: Centro de Recursos Humanos/UFBA.

- (1998b). "Reinventando fases: A família do idoso", Cadernos CRH, n. 1, Salvador: Centro de Recursos Humanos/UFBA, pp. 69-87.

Camarano, Ana Amélia (1999). Muito além dos 60: Os novos idosos brasileiros, Rio de Janeiro: Ipea.

CAndido, Antonio (1951). "The Brazilian family", in T. Lynn Smith \& Alexander Marchant (orgs), Brazil. Portrait of a half a continent, Nova York: The Dryden Press, pp. 291-312.

Carvalho, Edgard Assis (org) (1978), Antropologia econômica, São Paulo: Livraria Editora Ciências Humanas.

Chayanov, A. V. (1966). "The theory of peasant economy", in Kerblay Thorner \& Smith (eds), A. V. Chayanov on the theory of peasant economy, Homewood: American Economic Association/Richard D. Irwin.

Comissão Nacional de População e Desenvolvimento (CNPD) (2001). Migrações Internacionais: Contribuições para políticas, Brasília: CNPD.

Congresso Internacional de Americanistas (2009). CD dos Anais do 54ํㅡㄴ Congresso Internacional de Americanistas, México.

Couto, Mia (2009). O fio das missangas: Contos, São Paulo, Cia das Letras.

Debert, Guita Grin (1999). "A reinvenção da velhice", São Paulo: Edusp-Fapesp. 
EISENSTADT, Samuel N. (1976). De geração em geração, São Paulo: Perspectiva.

Engels, Friedrich (2007). A origem da família, da propriedade privada e do Estado, São Paulo: Escala.

ElIAs, Norberto (1990). O processo civilizador: Uma história dos costumes, Rio de Janeiro: Zahar.

Hareven, Tâmara (ed) (1978). Transitions: The family and the life course transitions, Londres: Tavistock.

Fernandiz, Francisco \& Feixa, Carles (eds) (2005). Jóvenes sin trégua: Culturas y políticas de la violência, Barcelona: Anthropos.

Fundação Instituto Brasileiro de Geografia e Estatística (FIBGE) (2002). Perfil dos idosos responsáveis pelos domicílios no Brasil 2000, "Série Estudos e Pesquisas", n. 9, Rio de Janeiro: IBGE.

FonsECA, Claudia (2007). "Apresentação - de família, reprodução e parentesco: Algumas considerações", Cadernos Pagu, n. 29, Campinas (disponível em http://www.scielo.br/scielo.php?script=sci_arttext\&pid=S010483332007000200002\#nt.

FoRTES, Meyer (1958). "Introduction", in Jack Goody \& Meyer Fortes, The developmental cycle in domestic groups, Londres: Cambridge University.

Franch Gutierrez, Mônica (2008). "Tempos, contratempos e passatempos: Um estudo sobre práticas e sentidos do tempo entre jovens de grupos populares do Grande Recife", tese de doutoramento em antropologia, Rio de Janeiro: IFCS/UFRJ.

FreYre, Gilberto (1967). Sobrados e mucambos, Rio de Janeiro, José Olympio [1936].

(1969). Casa-grande \& senzala, 14. ed., Rio de Janeiro, José Olympio [1933].

GIDDENS, Anthony (1993). A transformação da intimidade: Sexualidade, amor e erotismo nas sociedades modernas, São Paulo: Editora da Unesp. 
GoldanI, Ana Maria (1993). "As famílias no Brasil contemporâneo e o mito da desestruturação", Cadernos Pagu, n. 1, pp. 67-110.

Goode, William J. (1964). The Family, Englewood Cliffs: Prentice Hall.

HANSEN, Karen Tranberg (2008). "Introduction: Youth and the city", in Hansen et alii, Youth and the city in the global South, Bloomington and Indianapolis: Indiana University Press, pp. 3-23.

Holanda, Sérgio Buarque de (1988). Raízes do Brasil, Rio de Janeiro, José Olympio [1936].

Jelin, Elizabeth (1994). "Las familias en América Latina", Isis Internacional Ediciones de las Mujeres, n. 20, pp. 75-106.

Johnson-Hanks, Jennifer (2002). "On the limits of life stages in ethnography: Toward a theory of vital conjunctures", American Anthropologist, Vol. 104, n. 3, pp. 865-880.

Latham, Michael E. (2000). Modernization as Ideology: American social science and "nation building" in the Kennedy Era, Chapel Hill, N.C.

LecCARd, Carmen (2005). "Facing Uncertainty: Temporality and biographies in the new century", Young, Vol. 13, n. 2, pp. 123-146.

LeITE, Dante Moreira (1969). O caráter nacional brasileiro: História de uma ideologia, 2. ed., São Paulo: Pioneira.

LeWIs, Oscar (1959). Five families, Nova York, Basic.

LINTON, Ralph (1979). Cultura e personalidade, São Paulo, Mestre Jou.

Lins de Barros, Myriam (1987). Autoridade e afeto: Avós, filhos e netos na família brasileira, Rio de Janeiro, Zahar.

— (org) (2006). Família e gerações, Rio de Janeiro: Editora FGV.

LÉvi-Strauss, Claude (1981). "A Família”, in Claude Lévi-Strauss, Melford Spiro \& Kathleen Gough, A família: Origem e evolução, "Coleção Rosa dos Ventos", Porto Alegre: Vila Martha. 
Mannheim, Karl (1951). O problema das gerações. Sociologia do conhecimento, Porto: Rés.

Martes, Ana Cristina Braga \& Fleischer, Soraya (2003). Fronteiras cruzadas, São Paulo: Paz e Terra.

MeAd, Margaret (1970). Conflito entre gerações, Lisboa, Dom Quixote.

- (1969). Sexo e temperamento em três sociedades primitivas, São Paulo: Perspectiva.

- (2001). Coming of age in Samoa: A psychological study of primitive youth for Western Civilization, Nova York: Perennial Classics.

Mead, Margaret \& Bateson, Gregory (1970). "The art and technology of field work", in Raul Naroll \& Ronald Cohen (eds), A handbook of method in cultural anthropology, Nova York, Columbia University.

Meillasoux, Claude (1997). Mulheres, celeiros e capitais, São Paulo: Afrontamento.

Morgan, Lewis H. (1976). A sociedade primitiva, Vols. I e 2, Lisboa/Rio de Janeiro: Editorial Presença/Martins Fontes.

MülleR, Elaine (2008). "A transição é a vida inteira: Uma etnografia sobre os sentidos e a assunção da adultez", tese de doutoramento no Programa de Pós-Graduação Antropologia, Recife: UFPE.

PARK, Robert (1952). Human communities: The city and human ecology, Glencoe: The Free Press.

Parsons, Talcott \& Bales, Robert F. (1955). Family, socialization and interaction process, Glencoe: The Free Press.

Poullıon, François (dir) (1978). A antropologia econômica, "Coleção Perspectivas do Homem", Lisboa: Editora 70.

Radcliffe-Brown, A. R. (1982). "Introdução", in A. R. Radcliffe-Brown \& Daryll Forde (orgs), Sistemas políticos africanos de parentesco e casamento. 2. ed. Lisboa: Fundação Gulbenkian. 
REDFIELD, Robert (1941). The folk culture of the Yucatán, Chicago: University of Chicago.

Rey, Pierre-Phillipe (1978). "O modo de produção de linhagem", in Edgard Assis Carvalho (org), Antropologia econômica, São Paulo: Livraria Editora Ciências Humanas.

SAHLINS, Marshall (1972). Stone age economics, Chicago: Aldine.

Scott, Parry (2004). "Família, gênero e poder no Brasil no século XX", Revista Brasileira de Informações Bibliográficas nas Ciências Sociais, Vol. 58, n. 1, pp. 29-78.

- (1990) "O homem na matrifocalidade: Gênero, percepção e experiências do domínio doméstico", Cadernos de Pesquisa, n. 73, São Paulo, pp. 38-47.

- (2005). "Família, moralidade e as novas leis", in Maria Betânia Ávila, Ana Paula Portella \& Verônica Ferreira (orgs), Novas legalidades e democratização da vida social: Família, sexualidade e aborto, Rio de Janeiro: Garamond.

- (2009). "Trocando a casa e a rua: Idosos e a inversão da construção de gênero em camadas populares urbanas", in Parry Scott \& Marion Quadros (orgs), A diversidade no Ibura: Gênero, geração e saúde num bairro popular do Recife, Recife: Editora Universitária UFPE, pp. 117-132.

- - - (2006). "Gerações, comunidades e o Programa Saúde da Família: Reprodução, disciplina e a simplificação administrativa", in Myriam Lins de Barros (org), Família e gerações, Rio de Janeiro: Editora FGV, pp. 107129.

- (2003). "Patriarcalismo e ideias salvacionistas", in R. P. Scott \& G. Zarur (orgs), Ideologia, fragmentação e diversidade na América Latina, Recife: Editora Universitária UFPE.

Scott, Parry; Athias, Renato \& Quadros, Marion Teodósio de (org). Saúde, sexualidade e famílias urbanas, rurais e indígenas, Recife: Editora Universitária UFPE, 2008. 
Tavares, Mauricio Antunes (2009), "Caminhos cruzados, trajetórias entrelaçadas: Vida social de jovens entre o campo e a cidade no sertão de Pernambuco", Tese de doutoramento, Programa de Pós-Graduação Sociologia, Recife: UFPE.

VAITSMAN, Jeni (1994). Flexíveis e plurais - identidade, casamento e família em circunstâncias pós-modernas, Rio de Janeiro: Rocco.

VAn Gennep, Arnold (1978). Os ritos de passagem, Petrópolis: Vozes.

VeLHo, Gilberto (1986). Subjetividade e sociabilidade: Uma experiência de geração, Rio de Janeiro: Zahar.

Waiselfisz, Julio Jacobo (2000). Mapa da violência: Os jovens no Brasil, Brasília, Unesco.

Willems, Emilio (1953). "The structure of the Brazilian family", Social Forces, 31, May.

WINCH, Robert F. (1963), The modern family, Nova York: Holt, Rinehart and Winston [1953].

Woortmann, Klaas (2001). "O modo de produção doméstico em duas perspectiva: Chayanov e Sahlhins", "Série Antropológica”, Brasília, UnB, 2001.

— (1984). "A família trabalhadora", Ciências Sociais Hoje, Rio de Janeiro, Anpocs.

- (1987). A família das mulheres, Rio de Janeiro/Brasília: Tempo Brasileiro/CNPq. 